\title{
Investigación Enactiva en Comunicación. Estudio comparativo de proyectos caso que aplican metodología y Software IEC
}

\author{
Sandra Massoni, Luciana Margherit y Mariana Piola \\ Instituto Nacional de Tecnología Agropecuaria \\ Imargherit@gmail.com
}

\begin{abstract}
Resumen
El trabajo compara siete proyectos que han utilizado metodología y software IEC en diferentes ámbitos. Se trata de casos que integran una investigación sobre la medición comunicacional en el entorno de equipos interdisciplinarios, radicada en la Universidad Nacional de Rosario. Se examinan las modalidades de aplicación de la metodología de la Investigación Enactiva en Comunicación (IEC) sobre una plataforma online de seguimiento y evaluación de indicadores comunicacionales en dimensiones múltiples. En la comparación se utilizan fichas de proyecto caso, entrevistas cerradas y abiertas, y grupos de discusión. De los resultados surge una ponderación de la integración del componente comunicacional a proyectos interdisciplinarios, así como una valoración de la IEC a través de sus diferentes técnicas, instrumentos y herramientas.

Palabras clave: Interdisciplina - Comunicación Estratégica - Software IEC

\section{Resumo}

O trabalho compara sete projetos que usaram a metodologia e o software IEC em diferentes áreas. São casos que integram uma pesquisa sobre medição comunicacional no ambiente de equipes interdisciplinares, sediada na Universidade Nacional de Rosário. As modalidades de aplicação da metodologia Enactive Communication Research Pesquisa Enactiva em Comunicação (IEC, pela sua sigla em espanhol) são examinadas em uma plataforma online para monitoramento e avaliação de indicadores comunicacionais em múltiplas dimensões. Na comparação, são usados arquivos de casos, entrevistas fechadas e abertas e grupos de discussão. A partir dos resultados, vem a ponderação da integração do componente de comunicação aos projetos interdisciplinares, bem como uma avaliação do da IEC através de suas diferentes técnicas, ferramentas instrumentos e ferramentas.

Palavras chave: Interdisciplinar - Comunicação Estratégica - Software IEC
\end{abstract}




\section{Introducción}

"La IEC es un nuevo tipo de investigación que se suma a las tipologías tradicionales en ciencias sociales con vistas a un trabajo necesariamente transdisciplinar que busca la enacción comunicacional, entendida como un especial proceso cognitivo de reconfiguración micro-macro social en dimensiones múltiples “ (Massoni 2016).

Este informe de investigación ${ }^{1}$ presenta los resultados de un estudio comparativo de proyectos caso que han utilizado metodología de Investigación Enactiva en Comunicación (IEC), examina los términos en los que los usuarios de técnicas, herramientas e instrumentos IEC diferencian y valoran la metodología aplicada, y registra si se la percibe o no como articuladora de la participación integrada y del diálogo de saberes en equipos interdisciplinarios de investigación.

El proyecto propone ${ }^{2}$ investigar la dimensión comunicacional en organizaciones de distintos ámbitos desde la metaperspectiva teórica y metodológica de la Comunicación Estratégica. La teoría de la Comunicación Estratégica Enactiva define a la comunicación como encuentro en la diversidad, un cambio social conversacional que enactúa (Massoni, 2003; 2013; 2016).

La propuesta consiste en generar un sistema de medición (tipología de indicadores + plataforma online) que permite valorar analíticamente el estado, avances y desarrollo de los procesos comunicacionales, considerando la fluidez y la complejidad del fenómeno en su multidimensionalidad (Massoni et al, 2017).

Se parte de reconocer que los indicadores son instrumentos analíticos que proporcionan medidas -cuantitativas y cualitativas- factibles de transformarse en escalas comunes, con la finalidad de facilitar su agregación y comparación. Cumplen con la función de dar a conocer en forma resumida aquellas situaciones que intencionalmente se ha decidido observar, y por lo tanto, identifican componentes que pueden ser objeto de algún tipo de medición y valoración de

1Algunos de los proyectos caso pueden conocerse en "Proyecto Específico Red de Comunicación Estratégica para la Apicultura Argentina" (Margherit, 2014), Proyecto Específico de Comunicación Estratégica en Lechería (Mascotti, 2014); Proyecto Regional Agroforestal para el Norte de Santa Fe (Massoni y Margherit, 2016); Proyecto Urbano Cultural Colectivo de Murgas (Dayub, 2016) 2 EI PID radicado como proyecto de investigación en el área de posgrado en la Facultad de Ciencia Política y RRII de la Universidad Nacional de Rosario, forma parte de la línea de Investigación de la Maestría en Comunicación Estratégica. Está integrado por Sandra Massoni (Directora), Mariana Piola, Mariana Mascotti, Javier Spagnolo, Luciana Margherit y Mateo Bussi. 
las transformaciones operadas. En tal sentido, se busca aportar al desarrollo de herramientas para la construcción, selección, relevamiento y registro de indicadores comunicacionales en distintas dimensiones -informativa, interaccional, ideológica y comunicacional- que posibiliten un monitoreo continuo de actividades, procesos y productos de comunicación en el marco de proyectos integrados por equipos interdisciplinarios.

Para ello, el software IEC es un desarrollo informático específicamente comunicacional que integra en una plataforma digital una base de datos que registra indicadores comunicacionales articulados a las siete operaciones de una IEC (ver Tabla 1, primera columna). Su objetivo es operativizar el despliegue de una estrategia comunicacional en dimensiones múltiples de manera de registrar las formas del encuentro sociocultural que va asumiendo la vinculación de los actores en el territorio de la investigación durante su implementación. Lo hace a través de un mapa dinámico online de las transformaciones, a partir de los datos que el usuario va cargando y la plataforma devuelve sistematizando según los indicadores comunicacionales examinados.

Los siete proyectos caso bajo estudio en este trabajo son los siguientes:

- Proyecto Específico Red de Comunicación Estratégica para la Apicultura Argentina

- Proyecto Específico de Comunicación Estratégica en Lechería

- Escuela de Comunicación Estratégica de Rosario

- Proyecto de Desarrollo Agropecuario para el Noreste de Buenos Aires I

- Proyecto Regional Agroforestal para el Norte de Santa Fe

- Proyecto Urbano Cultural colectivo de Murgas

- Programa Nacional para el Desarrollo y la Sustentabilidad de los Territorios

Este artículo tensiona las siguientes preguntas:

- ¿Cómo es la aplicación de la IEC desde la percepción de los usuarios de distintas disciplinas?

- ¿Supone desde la perspectiva de investigadores de distintos campos del saber ventajas comparativas frente a otras metodologías de investigación?

- ¿El software IEC requiere una aplicación integral o puede ser utilizado en operaciones parciales en el entorno de estrategias comunicacionales? 


\section{VREVCOm

\section{Metodología}

La metodología IEC analiza la multidimensionalidad del fenómeno comunicacional para operar transformaciones en las configuraciones actuales de las modalidades de vinculación intersubjetiva (Massoni, 2016).

“(..) se sustenta en una teoría de la comunicación que aborda el encuentro sociocultural, comprensiva y aplicable de modo general. Con técnicas, instrumentos y herramientas propias, (Tabla 1) examina con criterios de cientificidad a la multiplicidad de lo comunicacional, en términos del acoplamiento dinámico y evolutivo de sistemas complejos emergentes. Para ello investiga desde los autodispositivos colectivos propios del análisis comunicacional- a partir de las matrices socioculturales (MS) y las mediaciones, propiciando procesos situados de cambio social conversacional" (Massoni, 2018: 86)

En este trabajo se examinan proyectos que aplican distintas operaciones de IEC $^{3}$ utilizando las siguientes técnicas: fichas de proyecto, entrevistas cerradas y abiertas, y grupo de discusión. Los resultados se integran en tablas comparativas siguiendo las 7 operaciones del diseño de estrategias de comunicación como algoritmos fluidos y correlacionando las técnicas IEC aplicadas con las valoraciones globales de los investigadores participantes en los proyectos caso.

Tabla 1. Operaciones del algoritmo fluido en una IEC:

técnicas, instrumentos y herramientas. Metodología IEC

\begin{tabular}{|l|l|l|l|}
\hline Operación cognitiva & \multicolumn{1}{|c|}{ Técnica } & \multicolumn{1}{|c|}{$\begin{array}{c}\text { Instrumento } \\
\text { (ejemplo) }\end{array}$} & \multicolumn{1}{|c|}{$\begin{array}{c}\text { Herramienta } \\
\text { (ejemplo) }\end{array}$} \\
\hline 1. Diálogo de saberes & $\begin{array}{l}\text { Versión técnica } \\
\text { comunicacional }\end{array}$ & $\begin{array}{l}\text { Test de la } \\
\text { fotoproblema }\end{array}$ & VTC sintética \\
\hline $\begin{array}{l}\text { 2. Determinación del } \\
\text { tipo de encuentro } \\
\text { dominante }\end{array}$ & $\begin{array}{l}\text { Marcas de } \\
\text { racionalidad } \\
\text { comunicacional (MRC) }\end{array}$ & $\begin{array}{l}\text { Reconocimiento de } \\
\text { marcas de } \\
\text { racionalidad } \\
\text { comunicacional }\end{array}$ & Diseño mediante MRC \\
\hline $\begin{array}{l}\text { 3. Identificación de los } \\
\text { agentes semióticos y }\end{array}$ & $\begin{array}{l}\text { Mapeo } \\
\text { comunicacional de }\end{array}$ & $\begin{array}{l}\text { Diagrama de actores } \\
\text { por componente del }\end{array}$ & $\begin{array}{l}\text { Diagrama evolutivo de } \\
\text { actores }\end{array}$ \\
\hline
\end{tabular}

3 Para definiciones de técnicas, instrumentos y herramientas IEC consultar el Dossier temático de esta edición de REVCOM y otros trabajos como Metodologías de comunicación estratégica del inventario al encuentro sociocultural (Massoni: 2013) o Guia IEC (Massoni: 2015). 


\section{ReVcom \\ REVISTA CIENTIFICA DE LA REDCOM}

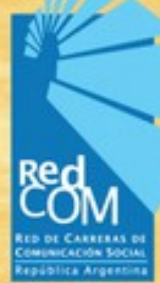

REVCOM | ISSN 2451-7836 | Año 4, \#8 | mayo de 2019 | Contribuciones | e008

\begin{tabular}{|l|l|l|l|}
\hline simbióticos & actores (MCA) & problema & \\
\hline $\begin{array}{l}\text { 4. Reconocimiento de } \\
\text { los autodispositivos } \\
\text { colectivos }\end{array}$ & $\begin{array}{l}\text { Matrices } \\
\text { socioculturales (MS) }\end{array}$ & $\begin{array}{l}\text { Test de modos y } \\
\text { formas }\end{array}$ & Caracterización de MS \\
\hline $\begin{array}{l}\text { 5. Diseño y co- diseño } \\
\text { de espacios y } \\
\text { productos } \\
\text { comunicacionales }\end{array}$ & $\begin{array}{l}\text { Árbol de soluciones } \\
\text { (AS) }\end{array}$ & $\begin{array}{l}\text { Prototipado evolutivo } \\
\text { de tecnologías } \\
\text { sociales, productos y } \\
\text { espacios de } \\
\text { comunicación }\end{array}$ & $\begin{array}{l}\text { Matriz escalonada de } \\
\text { planificación } \\
\text { concertada } \\
\text { de acciones, } \\
\text { proyectos, programas } \\
\text { y políticas de } \\
\text { comunicación }\end{array}$ \\
\hline $\begin{array}{l}\text { 6. Diseño y realización } \\
\text { de la investigación de } \\
\text { campo }\end{array}$ & Matrices de datos IEC & $\begin{array}{l}\text { Matriz de datos IEC } \\
\text { por MS }\end{array}$ & $\begin{array}{l}\text { Matriz de datos IEC } \\
\text { escalonada }\end{array}$ \\
\hline $\begin{array}{l}\text { 7. Reconfiguración } \\
\text { micro macro social del } \\
\text { encuentro en la } \\
\text { diversidad }\end{array}$ & $\begin{array}{l}\text { Plan operativo inicial } \\
\text { de la estrategia } \\
\text { comunicacional }\end{array}$ & $\begin{array}{l}\text { Matriz de planificación } \\
\text { de acciones, } \\
\text { proyectos, programas } \\
\text { y políticas. }\end{array}$ & $\begin{array}{l}\text { Ejes y tonos de } \\
\text { comunicación por MS }\end{array}$ \\
\hline
\end{tabular}

Massoni, 2018. Revista ALAIC N² 28

Las entrevistas se aplicaron y concretaron en el mes de octubre de 2018 con 16 investigadores participantes en el PID en curso. Para el grupo de discusión se seleccionaron dos participantes por proyecto caso, teniendo en cuenta que uno fuese un profesional con funciones de coordinación y el otro un comunicador que hubiera cargado en la plataforma digital. La muestra quedó conformada por 19 participantes de los 7 proyectos caso.

Cada uno de los equipos de los proyectos caso realizó un encuentro previo con la finalidad de volver a vincular los objetivos del PID con lo realizado en cada proyecto en particular. La realización del grupo de discusión se concretó el 26 de octubre de 2018, con participantes de 10 ciudades de Argentina (Trelew, Balcarce, General Villegas, San Pedro, Rosario, Victoria, Rafaela, Catamarca, Reconquista y Corrientes).

\section{Resultados}

Para la estructuración del análisis comparativo de los proyectos caso que utilizaron metodología y software IEC se trabajó con los siguientes ejes, los cuales han sido determinados para cada uno de los siete proyectos bajo estudio:

- Alcance, disciplinas y organizaciones participantes

- Experiencia de implementación de la metodología IEC 


\section{$\checkmark$ REVCOM \\ REVISTA CIENTIFICA DE LA REDCOM}

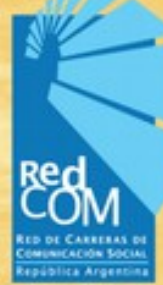

REVCOM | ISSN 2451-7836 | Año 4, \#8 | mayo de 2019 | Contribuciones | e008

- La medición comunicacional

\subsection{Alcance, disciplinas y organizaciones participantes}

En la Tabla 2 se presenta el alcance geográfico territorial de los proyectos caso bajo estudio.

Tabla 2. Proyectos caso que aplicaron técnicas y Software IEC

\begin{tabular}{|l|c|}
\hline Denominación del proyecto & Alcance \\
\hline $\begin{array}{l}\text { Proyecto Específico Red de Comunicación Estratégica para la } \\
\text { Apicultura Argentina }\end{array}$ & Nacional \\
\hline Proyecto Específico de Comunicación Estratégica en Lechería & Nacional \\
\hline Escuela de Comunicación Estratégica de Rosario & Internacional \\
\hline $\begin{array}{l}\text { Proyecto de Desarrollo Agropecuario para el Noreste de Buenos } \\
\text { Aires I }\end{array}$ & Regional \\
\hline Proyecto Regional Agroforestal para el Norte de Santa Fe & Regional \\
\hline Proyecto Urbano Cultural Colectivo de Murgas & Nacional \\
\hline $\begin{array}{l}\text { Programa Nacional para el Desarrollo y la Sustentabilidad de los } \\
\text { Territorios }\end{array}$ & \\
\hline
\end{tabular}

Se registraron tres casos de alcance nacional, dos de alcance regional, uno de alcance local y uno internacional.

En la Tabla 3 se presenta el ámbito de desarrollo y las organizaciones que llevaron adelante los proyectos IEC bajo estudio.

Tabla 3. Organizaciones y ámbitos de desarrollo que involucran los casos bajo estudio.

\begin{tabular}{|l|l|l|}
\hline Proyecto caso & Organización & Ámbito de desarrollo \\
\hline $\begin{array}{l}\text { Proyecto Específico Red de } \\
\text { Comunicación Estratégica para } \\
\text { la Apicultura Argentina }\end{array}$ & $\begin{array}{l}\text { Programa Nacional } \\
\text { Apícola }\end{array}$ & $\begin{array}{l}\text { Comunicación para el } \\
\text { desarrollo }\end{array}$ \\
\hline $\begin{array}{l}\text { Proyecto Específico de } \\
\text { Comunicación Estratégica en } \\
\text { Lechería }\end{array}$ & $\begin{array}{l}\text { Programa Nacional de } \\
\text { Leches }\end{array}$ & Comunicación rural \\
\hline $\begin{array}{l}\text { Escuela de Comunicación } \\
\text { Estratégica }\end{array}$ & ECER & Comunicación en ONG \\
\hline Proyecto de Desarrollo & Estación Experimental San & Comunicación para el \\
\hline
\end{tabular}

"Investigación Enactiva en Comunicación. Estudio comparativo de proyectos caso que aplican metodología y Software IEC"| Sandra Massoni, Luciana Margherit y Mariana Piola | https://doi.org/10.24215/24517836e008 | Pág. 6 


\begin{tabular}{|l|l|l|}
\hline $\begin{array}{l}\text { Agropecuario para el Noreste } \\
\text { de Buenos Aires I }\end{array}$ & Pedro & desarrollo \\
\hline $\begin{array}{l}\text { Proyecto Regional Agroforestal } \\
\text { para el Norte de Santa Fe }\end{array}$ & Colectivo autoorganizado & Comunicación ambiental \\
\hline $\begin{array}{l}\text { Proyecto Urbano Cultural } \\
\text { Colectivo de Murgas de } \\
\text { Rosario }\end{array}$ & $\begin{array}{l}\text { Colectivo de murgas estilo } \\
\text { uruguayo de Rosario }\end{array}$ & Comunicación cultural \\
\hline $\begin{array}{l}\text { Programa Nacional para el } \\
\text { Desarrollo y la Sustentabilidad } \\
\text { de los Territorios }\end{array}$ & $\begin{array}{l}\text { Instituto Nacional de } \\
\text { Tecnología Agropecuaria. }\end{array}$ & $\begin{array}{l}\text { Comunicación para el } \\
\text { desarrollo }\end{array}$ \\
\hline
\end{tabular}

Los casos bajo estudio ${ }^{4}$ corresponden al ámbito de la comunicación para el desarrollo (3), comunicación rural (1), comunicación en ONG (1), comunicación ambiental (1) y comunicación cultural (1). Las organizaciones corresponden al sector público (5 ) y a colectivos autoorganizados (2).

En la Tabla 4 se presentan datos sobre las disciplinas de base y de especialización de los equipos de trabajo en las IEC bajo estudio.

Tabla 4. Disciplinas que involucran los Proyecto Caso

\begin{tabular}{|l|l|}
\hline Proyecto caso & Campo disciplinar \\
\hline Proyecto Específico Red de Comunicación & Agronomía \\
Estratégica para la Apicultura Argentina & Veterinaria \\
& Biología \\
\hline
\end{tabular}

4 Para más información respecto de los proyectos se puede consultar: Massoni, S.y Margherit, L. (2016) Despliegue, seguimiento y evaluación de la estrategia comunicacional de un proyecto agroforestal mediante metodología de investigación enactiva en comunicación, en XII Congreso Nacional y V Internacional Sobre Democracia : la democracia por venir : elecciones, nuevos sujetos políticos, desigualdades, globalización / Franco Bartolacci ... [et al.] ; compilado por Franco Bartolacci ... [et al.]. 1a ed . - Rosario : UNR Editora. Editorial de la Universidad Nacional de Rosario; Massoni, Sandra H ; Piola, Mariana ; Bussi, Mateo. Un sistema de medición comunicacional más allá del control: Indicadores comunicacionales en dimensiones múltiples. En: Nueva teoría estratégica: Repensando la estrategia desde la comunicación / coordinadores Amaia Arribas; Raul Herrera Echenique y Rafael Alberto Pérez. -[Quito]: Universidad de los Hemisferios, 2017, cap. 7: p. 202-229.; Mascotti,M.; Spagnolo, J.; Margherit, L.; Piola, M. Investigación enactiva, el encuentro en la diversidad. En XVII Jornadas Nacionales de Extensión Rural y IX del Mercosur. En AADER - Facultad de Ciencias Agrarias, Universidad Nacional de Rosario Zavalla, Santa Fe. 19 al 21 de noviembre 2014 ; Mascotti, M. (2014) La comunicación estratégica en el. INTA lechero. Investigación enactiva para el encuentro sociocultural. UNR, Rosario. Disponible en https://rephip.unr.edu.ar/handle/2133/10741 ; Margherit, L. (2014) Estrategia de comunicación para la apicultura argentina. Una red conversacional. UNR, Rosario.; Dayub, J. 2016. "Cantar comunicación. Un proyecto de Comunicación Estratégica para el colectivo de Murgas Estilo Uruguayo de Rosario". UNR, Rosario. 


\begin{tabular}{|c|c|}
\hline & $\begin{array}{l}\text { Forestal } \\
\text { Administración } \\
\text { Desarrollo rural } \\
\text { Economía } \\
\text { Química } \\
\text { Genética } \\
\text { Zootecnia } \\
\text { Alimentación } \\
\text { Comunicación } \\
\text { Educación }\end{array}$ \\
\hline $\begin{array}{l}\text { Proyecto Específico de Comunicación } \\
\text { Estratégica en Lechería }\end{array}$ & $\begin{array}{l}\text { Agronomía } \\
\text { Veterinaria } \\
\text { Biotecnología } \\
\text { Economía } \\
\text { Desarrollo rural } \\
\text { Administración } \\
\text { Sociología } \\
\text { Educación } \\
\text { Genética } \\
\text { Agroindustria } \\
\text { Alimentación } \\
\text { Bienestar animal } \\
\text { Comercio exterior } \\
\text { Comunicación }\end{array}$ \\
\hline Escuela de Comunicación Estratégica & $\begin{array}{l}\text { Comunicación } \\
\text { Psicología } \\
\text { Odontología } \\
\text { Biología } \\
\text { Ciencia Política } \\
\text { Educación }\end{array}$ \\
\hline $\begin{array}{l}\text { Proyecto de Desarrollo Agropecuario para el } \\
\text { Noreste de Buenos Aires I }\end{array}$ & $\begin{array}{l}\text { Agronomía } \\
\text { Veterinaria } \\
\text { Desarrollo rural } \\
\text { Administración } \\
\text { Comunicación } \\
\text { Geografía } \\
\text { Fitopatología } \\
\text { Mejoramiento genético } \\
\text { Entomología } \\
\text { Agroecología } \\
\text { Agrometeorología }\end{array}$ \\
\hline
\end{tabular}




\begin{tabular}{|l|l|}
\hline \multirow{4}{*}{ Proyecto Urbano Cultural Colectivo de Murgas } & Comunicación \\
& Danza \\
& Escenografía \\
& Música \\
& Diseño \\
\hline & Agronomía \\
& Biología \\
& Forestal \\
Proyecto Regional Agroforestal para el Norte & Desarrollo rural \\
de Santa Fe & Economía \\
& Veterinaria \\
& Gestión institucional \\
Comunicación \\
\hline Programa Nacional para el Desarrollo y la & Agroecología \\
\hline Sustentabilidad de los Territorios & Desarrollo rural \\
& Sociología \\
& Antropología \\
& Ciencia Política \\
& Economía \\
& Geografía \\
& Comunicación \\
& Agronomía \\
\hline
\end{tabular}

Los proyectos caso bajo estudio dan cuenta de una diversa integración disciplinar de los equipos. En las IEC analizadas la comunicación aporta su especificidad y a la vez su convergencia permite operar sobre la complejidad de los problemas comunicacionales. Las técnicas IEC contemplan espacios interdisciplinarios para la concertación y articulación de los saberes disponibles. La Tabla 4 da cuenta de ese espesor, con la concurrencia de profesionales participantes en la aplicación de técnicas IEC entre 5 disciplinas como mínimo y 14 como máximo según los casos.

\subsection{Experiencia de implementación de la metodología IEC}

La Tabla 5 da cuenta de la diversidad de los casos abordados, describiendo sintéticamente cómo se inscriben las Estrategias de comunicación en cada situación y el estado actual de los mismos. 
Tabla 5. Proyectos caso bajo estudio en el PID 231

"Indicadores comunicacionales en dimensiones múltiples. Fase 2", Universidad Nacional de Rosario

\begin{tabular}{|c|c|}
\hline Proyecto caso & Descripción \\
\hline $\begin{array}{l}\text { Proyecto } \\
\text { Específico } \\
\text { Red de } \\
\text { Comunicación } \\
\text { Estratégica } \\
\text { para la } \\
\text { Apicultura } \\
\text { Argentina }\end{array}$ & $\begin{array}{l}\text { Se trata del abordaje del componente comunicacional del Programa } \\
\text { Nacional Apícola (PROAPI), en el período } 2009 \text { - } 2012 \text {. La apicultura es } \\
\text { una actividad productiva que se extiende por todo el país y que desde } \\
\text { INTA se impulsó con una mirada estratégica. En } 2009 \text { se incluyó el enfoque } \\
\text { de la IEC para concertar acciones para el desarrollo sostenible del sector. } \\
\text { El proyecto finalizó pero dejó consolidada una metodología de hacer } \\
\text { comunicación en la apicultura argentina. }\end{array}$ \\
\hline $\begin{array}{l}\text { Proyecto } \\
\text { Específico de } \\
\text { Comunicación } \\
\text { Estratégica en } \\
\text { Lechería }\end{array}$ & $\begin{array}{l}\text { Consiste en el diseño e implementación de una estrategia comunicacional } \\
\text { de la lechería bovina para toda la Argentina, del Programa Nacional Leches } \\
\text { del INTA, de } 2010 \text { a } 2012 \text {. El Proyecto de Comunicación Estratégica en } \\
\text { Lechería es transversal al Programa. } \\
\text { El proyecto finalizó y dejó consolidada una metodología de hacer } \\
\text { comunicación en la lechería argentina, que puede ser retomada en futuros } \\
\text { proyectos de esa área de trabajo.. }\end{array}$ \\
\hline $\begin{array}{l}\text { Escuela de } \\
\text { Comunicación } \\
\text { Estratégica de } \\
\text { Rosario }\end{array}$ & $\begin{array}{l}\text { Es el trabajo colaborativo y sinérgico de un grupo de investigadores de la } \\
\text { Comunicación Estratégica que -desde 2012- actúa desde esta } \\
\text { metaperspectiva. } \\
\text { Actualmente la investigación sigue en curso. }\end{array}$ \\
\hline $\begin{array}{l}\text { Proyecto de } \\
\text { Desarrollo } \\
\text { Agropecuario } \\
\text { para el } \\
\text { Noreste de } \\
\text { Buenos Aires } \\
\text { I }\end{array}$ & $\begin{array}{l}\text { Se refiere a la estrategia comunicacional del proyecto "Aportes para el } \\
\text { crecimiento, la equidad y la sustentabilidad del territorio diversificado de los } \\
\text { partidos costeros de San Pedro y Baradero", del INTA San Pedro. Desde un } \\
\text { enfoque de desarrollo territorial se integra investigación y extensión, desde } \\
\text { un enfoque territorial integra investigación - extensión con el aporte } \\
\text { metodológico de la IEC. } \\
\text { El proyecto finalizó pero tendrá continuidad en la nueva plataforma de } \\
\text { investigación y transferencia de ese territorio. }\end{array}$ \\
\hline $\begin{array}{l}\text { Proyecto } \\
\text { Regional } \\
\text { Agroforestal } \\
\text { para el Norte } \\
\text { de Santa Fe }\end{array}$ & $\begin{array}{l}\text { Este caso es implementado por el Grupo de trabajo en sistemas } \\
\text { agroforestales integrado por técnicos de organizaciones vinculadas al } \\
\text { sector, en el norte de Santa Fe. Busca promover la conservación mediante } \\
\text { el ordenamiento territorial de los bosques nativos, la regulación de la } \\
\text { expansión de la frontera agropecuaria y de cualquier otro cambio de uso de } \\
\text { suelo. } \\
\text { El proyecto sigue aplicando las técnicas IEC en su dinámica de trabajo. }\end{array}$ \\
\hline $\begin{array}{l}\text { Proyecto } \\
\text { Urbano } \\
\text { Cultural } \\
\text { Colectivo de } \\
\text { Murgas }\end{array}$ & $\begin{array}{l}\text { Es un proyecto de comunicación artístico cultural del Colectivo de Murgas } \\
\text { estilo uruguayo, que convoca a } 17 \text { agrupaciones de la ciudad de Rosario, } \\
\text { Santa Fe. Tiene como finalidad generar una transformación conversacional } \\
\text { a partir de la IEC. } \\
\text { El colectivo continúa y las metodologías de la Comunicación estratégica } \\
\text { desplegadas en este caso confluyen en un trabajo articulado que sigue en } \\
\text { curso. }\end{array}$ \\
\hline
\end{tabular}




\section{Programa Nacional para el Desarrollo y la \\ Sustentabilida d de los Territorios}

Este caso aborda el trabajo realizado en un proyecto interdisciplinario del INTA, que se desarrolló entre 2014 y 2018. Su finalidad fue comprender las transformaciones territoriales, los procesos de innovación y fortalecer las competencias para la gestión del desarrollo y la sustentabilidad del territorio argentino.

El caso trata de la estrategia comunicacional desplegada con el equipo de gestión del proyecto. Constituye el punto de partida para pensar el componente comunicacional en la reformulación institucional del mismo.

El estudio de la experiencia de implementación y uso de técnicas y software IEC se realizó en el año 2018 , con la participación de 19 investigadores participantes en el PID en curso. Se seleccionaron dos participantes por proyecto caso, teniendo en cuenta que uno fuera un profesional con funciones de coordinación y el otro un comunicador que hubiera cargado en la plataforma digital. La muestra quedó conformada por 16 participantes de los 7 proyectos caso.

Se presenta la valorización de la IEC vinculado al trabajo en el territorio y al trabajo en equipos interdisciplinarios en la percepción de los entrevistados (Figuras 1 y 2 ).

Figura 1. Valorización del aporte del diseño de estrategias de comunicación al trabajo en el territorio

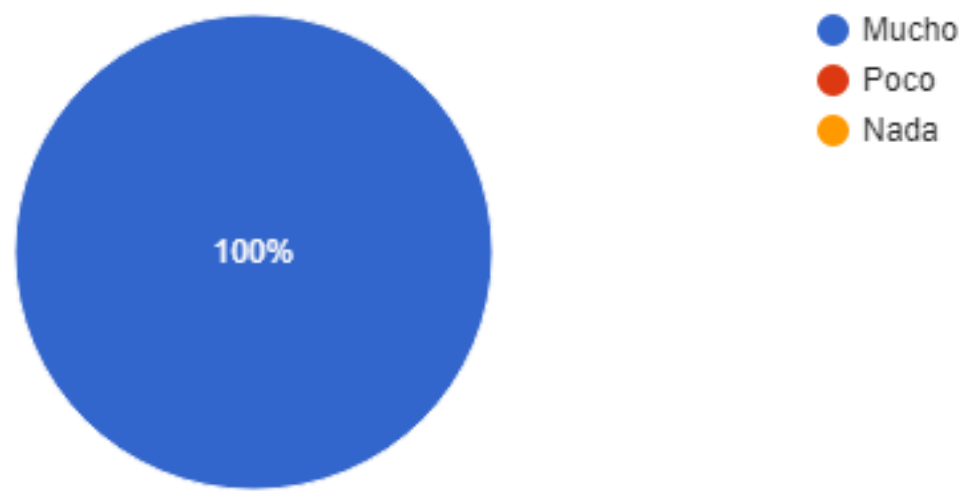


REVCOM | ISSN 2451-7836 | Año 4, \#8 | mayo de 2019 | Contribuciones | e008

Figura 2. Valorización del aporte del diseño de estrategias de comunicación al trabajo interdisciplinario

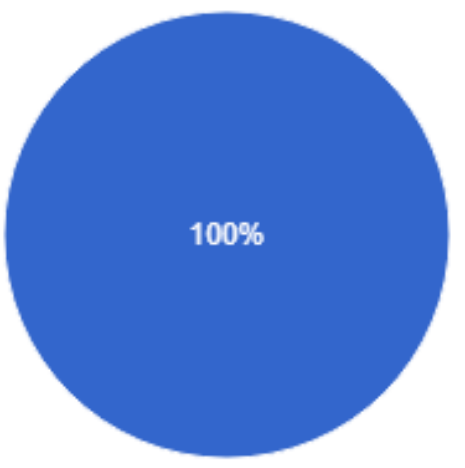

Mucho

Poco

Nada

En las entrevistas se solicitó valoración en torno a cuánto se considera que las estrategias de comunicación aportan al trabajo territorial y el $100 \%$ de los participantes respondió que "mucho" (Figura 1). La misma respuesta obtuvo la consulta en torno al aporte en la conformación de equipos interdisciplinarios (Figura 2).

En la misma línea, se indagó cuál considera que es el principal aporte del diseño de estrategias de comunicación desde esta metaperspectiva al proyecto a partir de las variables: organizador, articulador, innovador, útil y eficiente (Figura 3).

Figura 3. Valorización en base a la experiencia propia de esta metaperspectiv

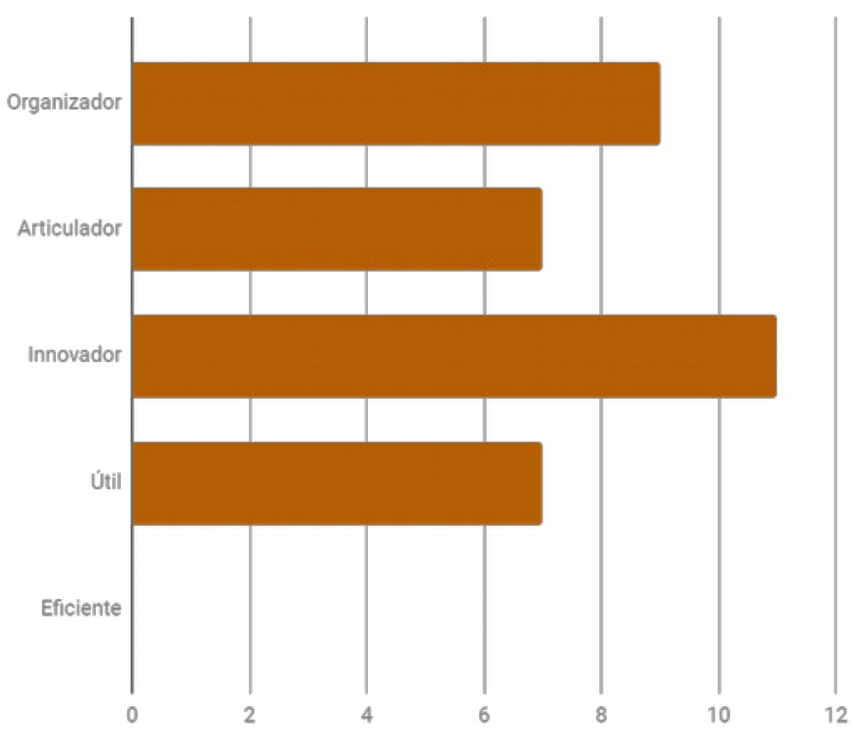

a

La calificación más recurrente del aporte fue "innovador", seguido por "organizador". 


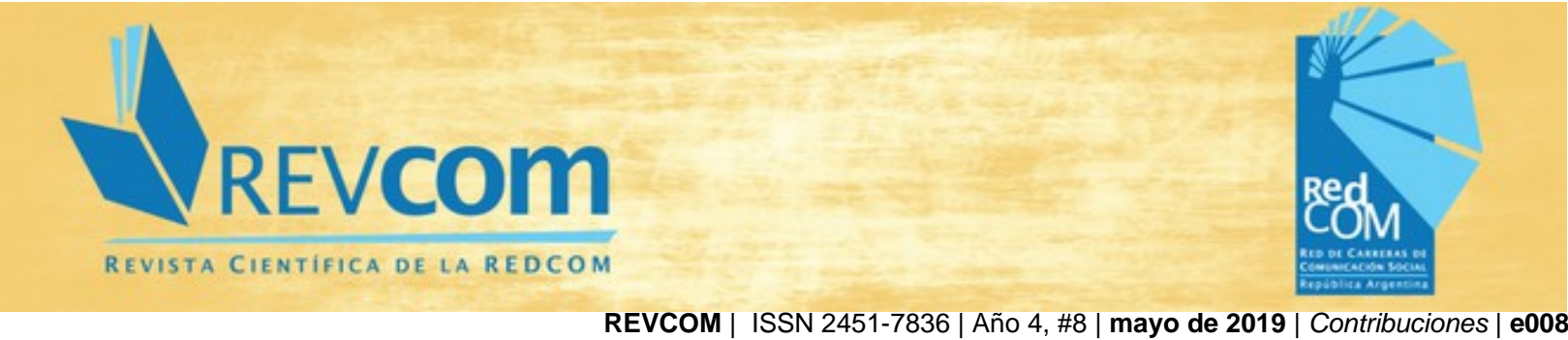

Todos los participantes consideran que las estrategias de comunicación desplegadas desde la IEC aportan al trabajo en el territorio y también en equipos interdisciplinarios. La consideran una metaperspectiva "innovadora y disparadora de discusiones y acciones direccionadas con mayor especificidad a las transformaciones que se buscan promover en los proyectos". En el mismo sentido, aparece la idea de que se trata de "una buena oportunidad para incorporar un registro más complejo de la comunicación a la planificación desde un lugar capaz de interpelar a los gestores".

Se solicitó a los participantes calificar la experiencia en el uso de técnicas de Comunicación Estratégica en cada caso (Figura 4).

Figura 4. Calificación de experiencia de uso de técnicas IEC en su proyecto/equipo

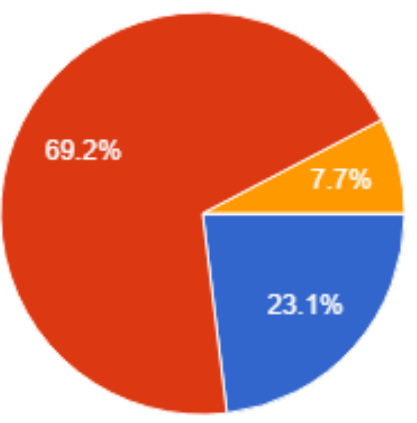

Muy satisfactoria

Satisfactoria

Poco satisfactoria

Nada satisfactoria

La mayoría de los participantes reconocen como satisfactoria y muy satisfactoria la experiencia de incorporación de la IEC en sus proyectos como una propuesta "novedosa" y ahora "un componente estratégico" que "puede usarse transversalmente".

Los referentes entrevistados argumentan su satisfacción por la introducción de la comunicación como disciplina desde el comienzo de los proyectos debido a su integralidad respecto de otras metodologías. "Propone una mirada holística". Quienes puntualizan dificultades en la implementación de la metodología, las vincularon a cierta resistencia a que "un comunicador lidere esta parte del proceso de investigación interdisciplinaria" y con "la terminología utilizada". Cuando se consideró poco satisfactoria, se fundamentó en que se implementó la IEC cuando el proyecto ya estaba avanzado, por esta razón les "faltó tiempo para aprovecharla". 
La tabla 6 expone cuáles fueron las técnicas IEC aplicadas en cada proyecto caso.

Tabla 6. Técnicas IEC aplicadas en cada proyecto caso.

\begin{tabular}{|c|c|c|c|c|c|c|c|}
\hline Proyecto caso & $\begin{array}{l}\text { Versión } \\
\text { Técnica } \\
\text { Comuni- } \\
\text { cacional }\end{array}$ & $\begin{array}{c}\text { Marcas } \\
\text { de Racio- } \\
\text { nalidad } \\
\text { Comunic } \\
\text { acional } \\
\text { (MRC) }\end{array}$ & $\begin{array}{c}\text { Mapeo } \\
\text { comuni- } \\
\text { cacional } \\
\text { de } \\
\text { actores } \\
\text { (MCA) }\end{array}$ & $\begin{array}{l}\text { Matrices } \\
\text { Socio- } \\
\text { cultural } \\
\text { es (MS) }\end{array}$ & $\begin{array}{l}\text { Árbol de } \\
\text { Solu- } \\
\text { ciones } \\
\text { (AS) }\end{array}$ & $\begin{array}{c}\text { Matrices } \\
\text { de } \\
\text { Datos } \\
\text { IEC }\end{array}$ & $\begin{array}{c}\text { Plan } \\
\text { operativo } \\
\text { inicial de } \\
\text { la } \\
\text { estrategia } \\
\text { comuni- } \\
\text { cacional }\end{array}$ \\
\hline $\begin{array}{l}\text { Proyecto Específico } \\
\text { Red de } \\
\text { Comunicación } \\
\text { Estratégica para la } \\
\text { Apicultura Argentina }\end{array}$ & $\mathrm{x}$ & $x$ & $x$ & $\mathrm{x}$ & $x$ & $\mathrm{x}$ & $\mathrm{x}$ \\
\hline $\begin{array}{l}\text { Proyecto Específico } \\
\text { de Comunicación } \\
\text { Estratégica en } \\
\text { Lechería }\end{array}$ & $x$ & $x$ & $x$ & $x$ & $\mathrm{x}$ & $x$ & $x$ \\
\hline $\begin{array}{l}\text { Escuela de } \\
\text { Comunicación } \\
\text { Estratégica }\end{array}$ & $x$ & $\mathrm{x}$ & $x$ & $\mathrm{x}$ & $x$ & & \\
\hline $\begin{array}{l}\text { Proyecto de } \\
\text { Desarrollo } \\
\text { Agropecuario para el } \\
\text { Noreste de Buenos } \\
\text { Aires I }\end{array}$ & $x$ & $x$ & $x$ & $x$ & $\mathrm{x}$ & & \\
\hline $\begin{array}{l}\text { Proyecto Regional } \\
\text { Agroforestal para el } \\
\text { Norte de Santa Fe }\end{array}$ & $\mathrm{x}$ & $\mathrm{x}$ & $x$ & $x$ & $\mathrm{x}$ & & \\
\hline $\begin{array}{l}\text { Proyecto Urbano } \\
\text { Cultural Colectivo de } \\
\text { Murgas }\end{array}$ & $x$ & & & & $x$ & & \\
\hline $\begin{array}{l}\text { Programa Nacional } \\
\text { para el Desarrollo y la } \\
\text { Sustentabilidad de } \\
\text { los Territorios }\end{array}$ & $\mathrm{x}$ & & $\mathrm{x}$ & & $x$ & & $\mathrm{x}$ \\
\hline
\end{tabular}




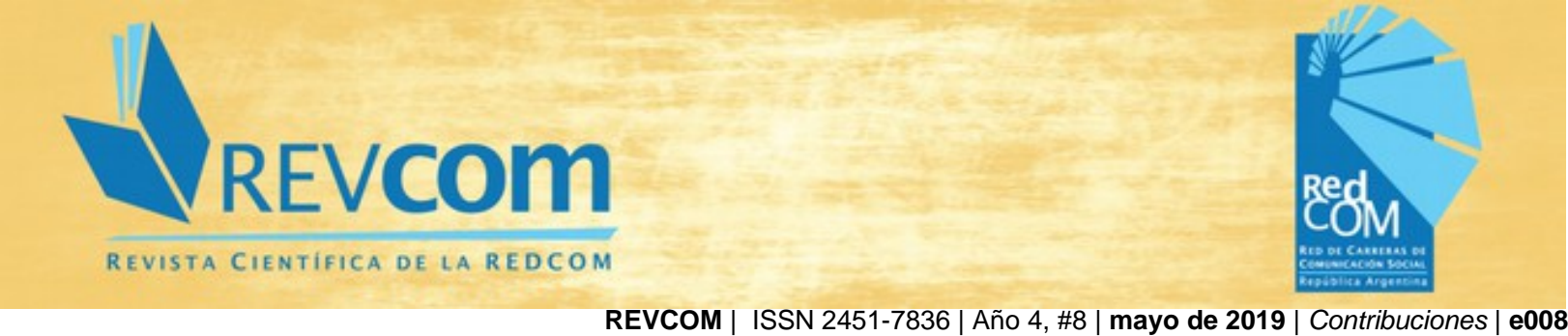

La tabla da cuenta de la disparidad en la aplicación de operaciones, técnicas, herramientas e instrumentos de los proyectos bajo estudio. Sólo en dos de los casos se aplicaron 7 pasos; en 3 casos fueron 5 y en los restantes, 4 y 2 respectivamente.

Respecto del eje de comparación de la metodología IEC y otras experiencias de incorporación de la comunicación a los proyectos, las menciones de los entrevistados encuentran diferencias que se exponen en la Figura 5.

Figura 5. Diferencias encontradas entre IEC y otras experiencias de integración de la comunicación a los proyectos.

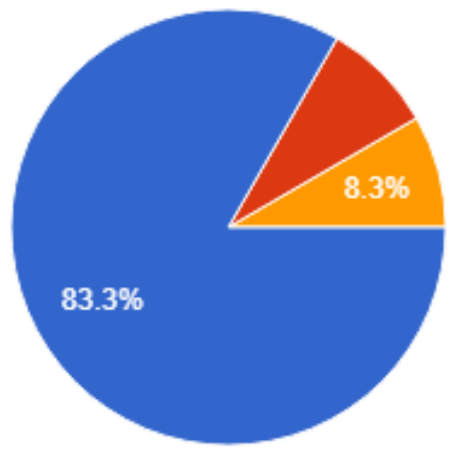

Siempre

Casi siempre

Algunas veces

Nunca

En las respuestas se destaca el reconocimiento de la complejidad del registro comunicacional que se abre a partir de la incorporación de la metodología de la IEC en los proyectos. Los participantes ponderan el involucramiento del comunicador "desde el comienzo del proyecto", "esto habilita otro tipo de ejercicio y apropiación del aporte de la comunicación por parte del equipo interdisciplinario". La flexibilidad de las técnicas, instrumentos y herramientas de la IEC permite que aún en los casos en que no se han realizado todos los pasos de la metodología, se reconozcan aportes superadores frente a las formas tradicionales de investigación comunicacional. Valoran especialmente la "visión más sistémica del problema" y la "integralidad del enfoque que se toma desde el principio".

La Tabla 7 da cuenta de las dimensiones comunicacionales abordadas y registradas en el Software IEC en cada proyecto caso. 


\section{ReVcom \\ REVISTA CIENTIFICA DE LA REDCOM}

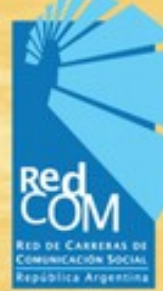

REVCOM | ISSN 2451-7836 | Año 4, \#8 | mayo de 2019 | Contribuciones | e008

Tabla 7. Carga por dimensiones en el Software IEC

\begin{tabular}{|l|c|c|c|}
\hline Proyecto caso & $\begin{array}{c}\text { Dimensión } \\
\text { Informativa }\end{array}$ & $\begin{array}{c}\text { Dimensión } \\
\text { Interaccional }\end{array}$ & $\begin{array}{c}\text { Dimensión } \\
\text { Ideológica }\end{array}$ \\
\hline Programa Nacional de Apicultura & $\mathbf{x}$ & $\mathbf{x}$ & $\mathbf{x}$ \\
\hline $\begin{array}{l}\text { Pro y e c to E s p e cíf i c o d e } \\
\text { Comunicación Estratégica en } \\
\text { Lechería }\end{array}$ & $\mathbf{x}$ & $\mathbf{x}$ & $\mathbf{x}$ \\
\hline $\begin{array}{l}\text { Escuela de Comunicación } \\
\text { Estratégica de Rosario. }\end{array}$ & $\mathbf{x}$ & $\mathbf{x}$ & \\
\hline $\begin{array}{l}\text { Proyecto de Desarrollo } \\
\text { Agropecuario para el Noreste de } \\
\text { Buenos Aires I }\end{array}$ & $\mathbf{x}$ & $\mathbf{x}$ & \\
\hline $\begin{array}{l}\text { Proyecto Regional Agroforestal } \\
\text { para el Norte de Santa Fe }\end{array}$ & $\mathbf{x}$ & $\mathbf{x}$ & $\mathbf{x}$ \\
\hline $\begin{array}{l}\text { Proyecto Urbano Cultural } \\
\text { Colectivo de Murgas }\end{array}$ & $\mathbf{x}$ & $\mathbf{x}$ & \\
\hline $\begin{array}{l}\text { Programa Nacional para el } \\
\text { Desarrollo y la Sustentabilidad de } \\
\text { los Territorios }\end{array}$ & $\mathbf{x}$ & $\mathbf{x}$ & \\
\hline
\end{tabular}

Figura 6 - Fichas de los proyectos

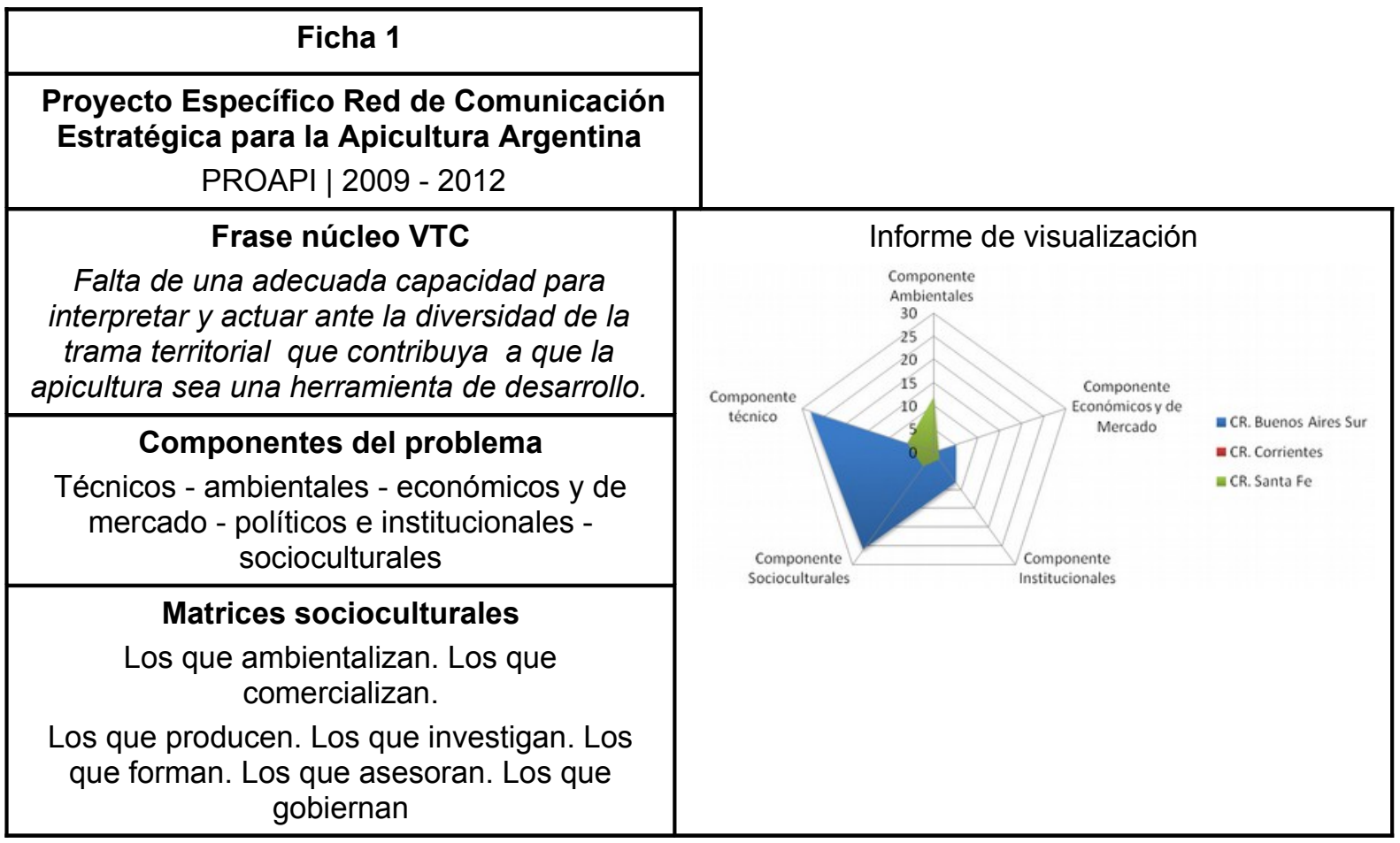




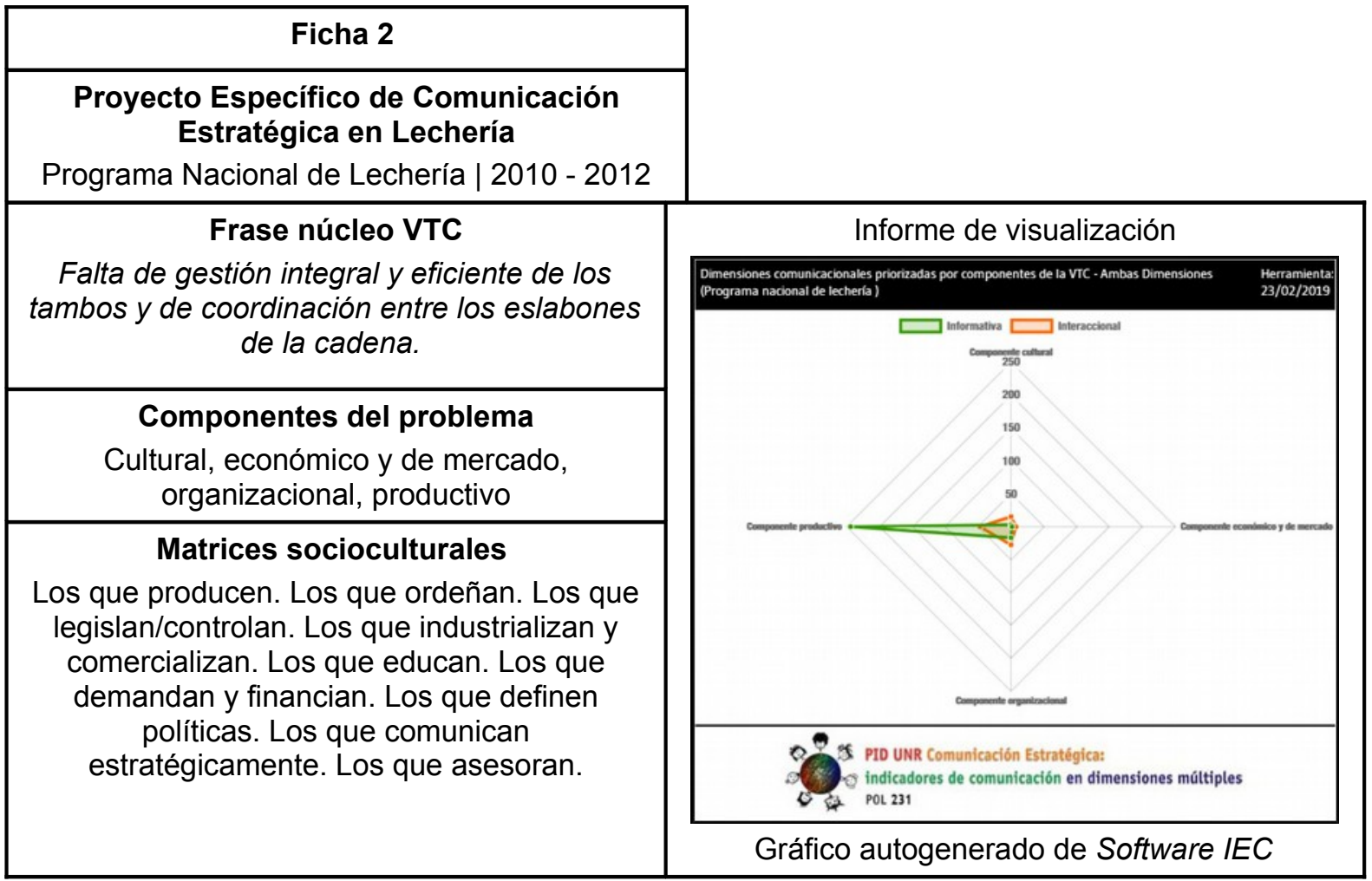

\begin{tabular}{|c|c|}
\hline \multicolumn{2}{|c|}{ Ficha 3 } \\
$\begin{array}{c}\text { Escuela de Comunicación Estratégica de } \\
\text { Rosario }\end{array}$ \\
$\begin{array}{c}\text { Escuela de Comunicación Estratégica de } \\
\text { Rosario | 2011.. }\end{array}$ \\
\hline $\begin{array}{c}\text { Frase núcleo VTC } \\
\text { Visión/configuración reduccionista de la } \\
\text { comunicación limitada a lo comunicativo. }\end{array}$ \\
\hline $\begin{array}{c}\text { Componentes del problema } \\
\text { Sociocultural, teórico metodológico, } \\
\text { económico, profesional, político legislativo }\end{array}$ \\
\hline $\begin{array}{c}\text { Matrices socioculturales } \\
\text { Los que comercializan la comunicación. Los } \\
\text { que comunican estratégicamente. Los que } \\
\text { demandan y financian. Los que educan. Los } \\
\text { que instrumentan la comunicación. Los que se } \\
\text { forman en comunicación. Los que validan }\end{array}$ \\
\hline
\end{tabular}

\section{Ficha 4}

"Investigación Enactiva en Comunicación. Estudio comparativo de proyectos caso que aplican metodología y Software IEC" | Sandra Massoni, Luciana Margherit y Mariana Piola | https://doi.org/10.24215/24517836e008 | Pág. 17 


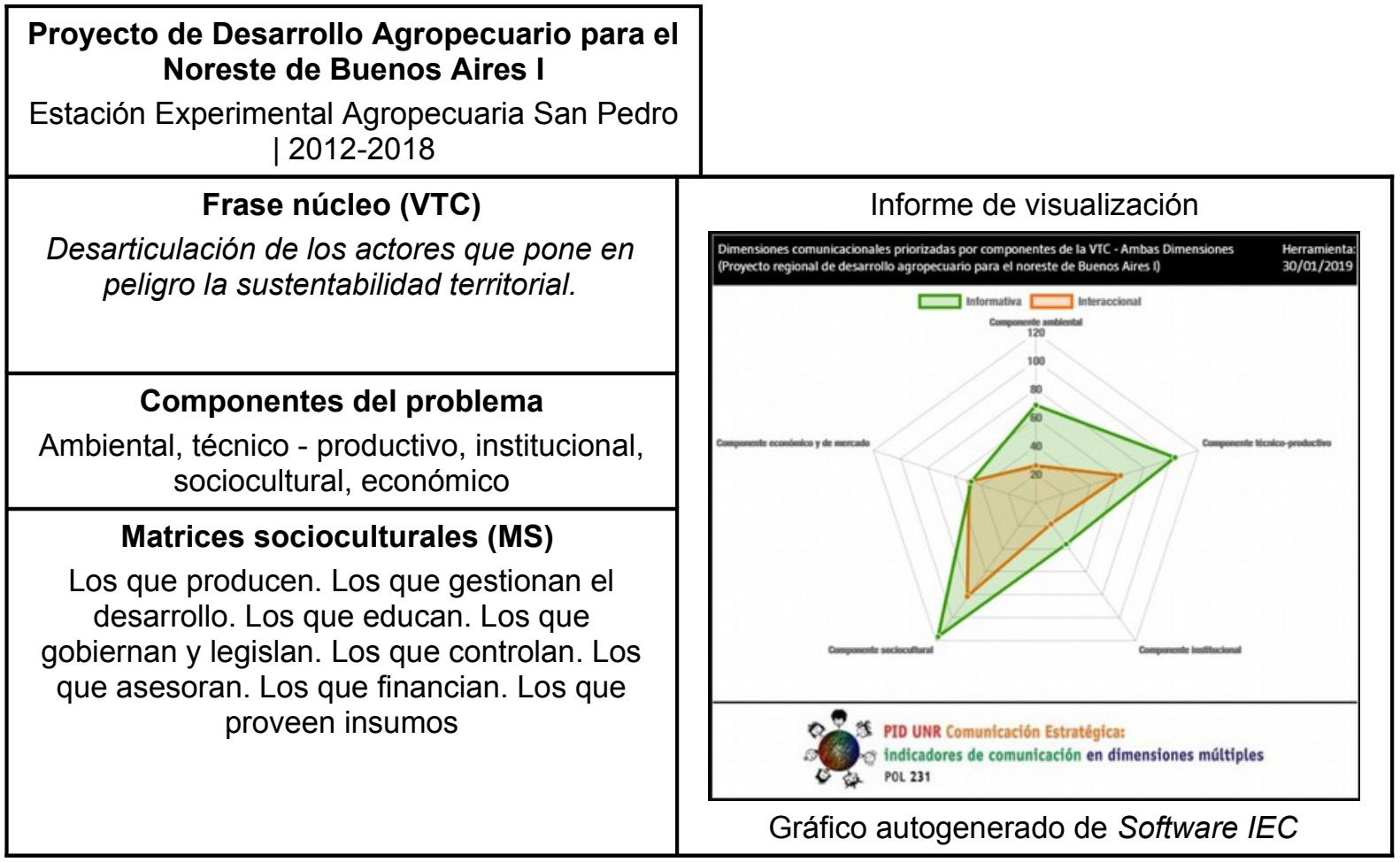

\begin{tabular}{|c|c|}
\hline \multicolumn{2}{|c|}{ Ficha 5} \\
\hline $\begin{array}{c}\text { Proyecto Regional Agroforestal para el Norte } \\
\text { de Santa Fe } \\
\ldots \mid 2010 \ldots\end{array}$ \\
$\begin{array}{c}\text { Fesde INTA no tenemos una mirada } \\
\text { compartida del bosque por lo que generamos } \\
\text { acciones dispersas y segmentadas. }\end{array}$ \\
\hline $\begin{array}{c}\text { Componentes del problema } \\
\text { écnico, político-institucional, ambiental, } \\
\text { económico y de mercado, sociocultural. }\end{array}$ \\
\hline $\begin{array}{c}\text { Matrices socioculturales } \\
\text { Los que producen, Los que asesoran, Los } \\
\text { que forman, Los que producen, Los que } \\
\text { asesoran, Los que producen }\end{array}$
\end{tabular}




\begin{tabular}{|c|c|}
\hline Ficha 6 & \\
\hline Colectivo de Murgas Rosario & \\
\hline $\begin{array}{c}\text { Frase núcleo VTC } \\
\text { Incipientes espacios comunes que articulen los } \\
\text { objetivos del Colectivo. }\end{array}$ & \multirow[t]{3}{*}{$\begin{array}{l}\text { Informe de visualización: Mapeo comunicacional } \\
\text { de actores. Aspecto: Ideológico }\end{array}$} \\
\hline $\begin{array}{l}\text { Componentes del problema } \\
\text { Cultural, ideológico y de sustentabilidad }\end{array}$ & \\
\hline $\begin{array}{c}\text { Matrices socioculturales } \\
\text { Los que hacen el colectivo. Los que subsidian. } \\
\text { Los que co-inspiran con las murgas del } \\
\text { Colectivo. Los que se auto-organizan en el arte. } \\
\text { Los que regulan la cultura }\end{array}$ & \\
\hline
\end{tabular}




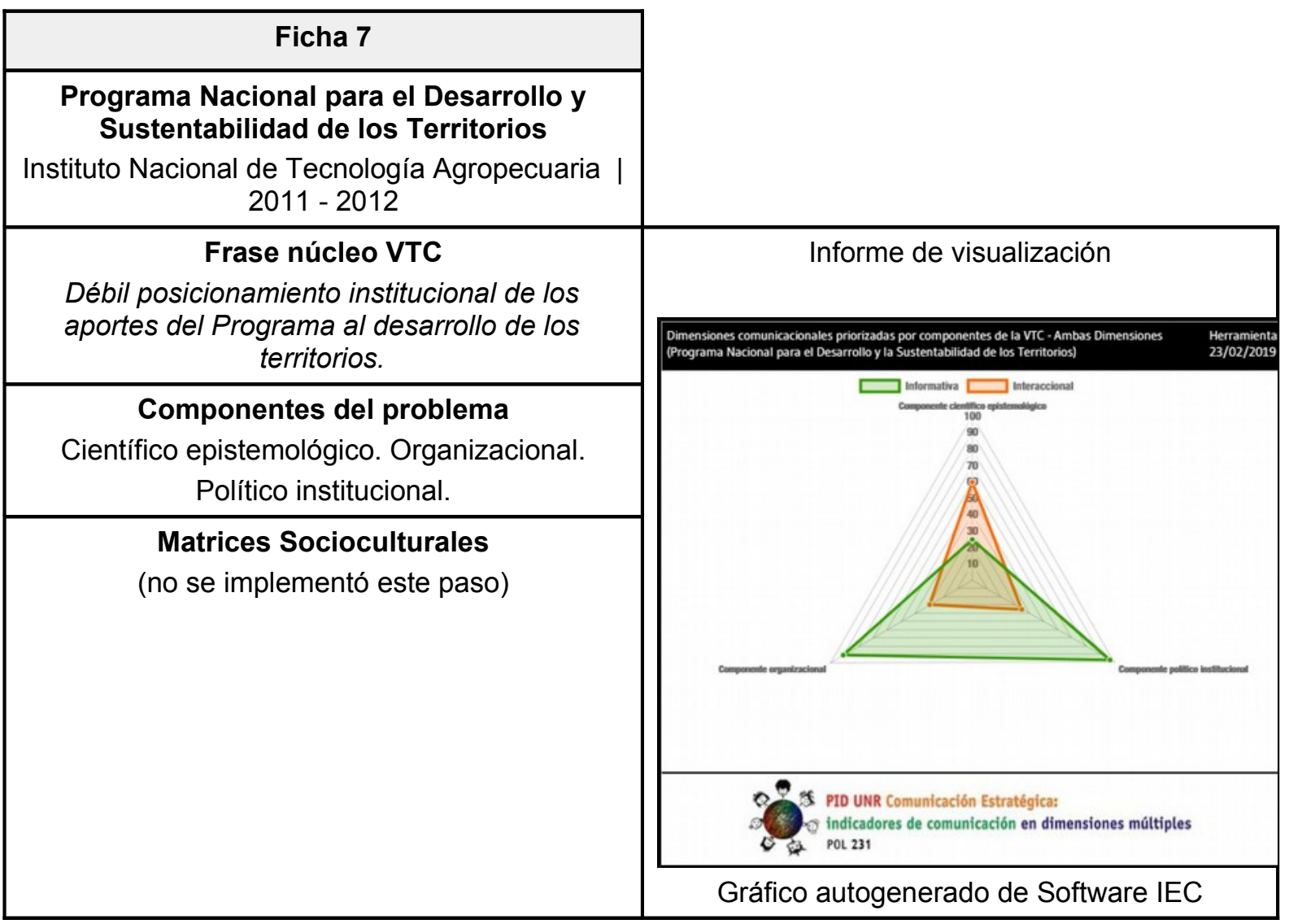

\subsection{La medición comunicacional}

Los integrantes del Grupo de discusión asociaron a la medición realizada con este Sistema de indicadores comunicacionales las palabras que se presentan en la Figura 7.

Figura 7. Nube de palabras asociadas al sistema de medición comunicacional del PID con tamaño según repeticiones.

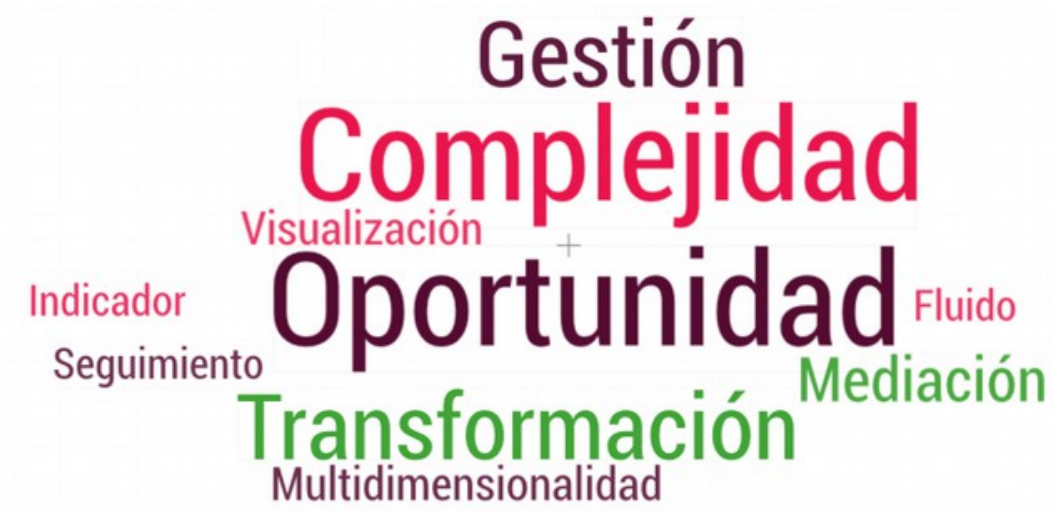

"Investigación Enactiva en Comunicación. Estudio comparativo de proyectos caso que aplican metodología y Software IEC" | Sandra Massoni, Luciana Margherit y Mariana Piola | https://doi.org/10.24215/24517836e008 | Pág. 20 


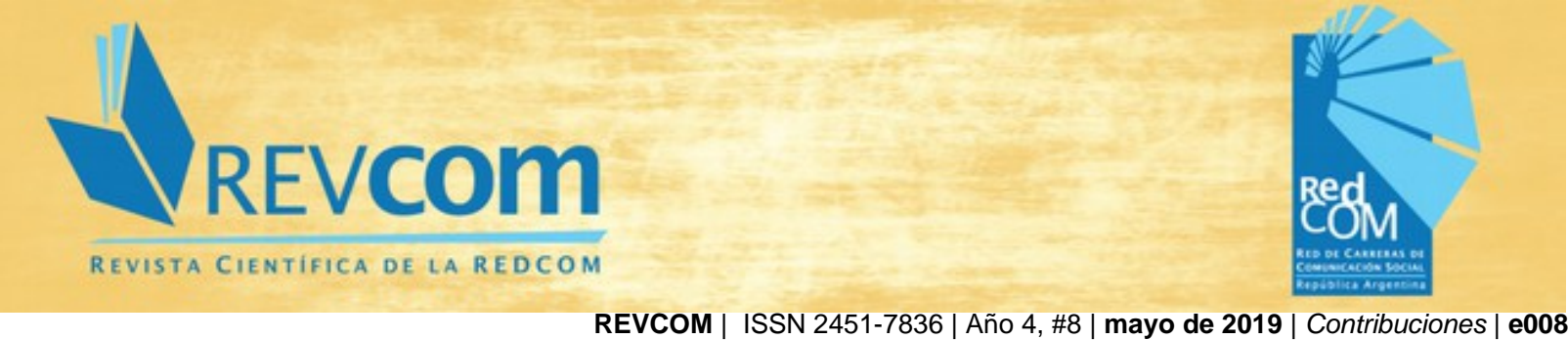

Los participantes valoran especialmente la posibilidad de medir superando el inventario de productos y espacios - mientras la estrategia de comunicación se va desplegando- y la posibilidad de visualización online de los resultados durante el proceso, "por la oportunidad de ir reflexionando acerca de su implementación al interior del equipo de gestión de los proyectos y organizaciones". Las palabras más destacadas en la "nube de palabras" son: "complejidad" y "oportunidad".

Todos los participantes afirman que utilizarían el sistema de medición en nuevos proyectos. La Figura 8 muestra que el total de los entrevistados afirman que les interesa utilizar el software IEC en futuros proyectos.

Figura 8. Consideración de la posibilidad de utilizar el sistema de medición en nuevos proyectos.

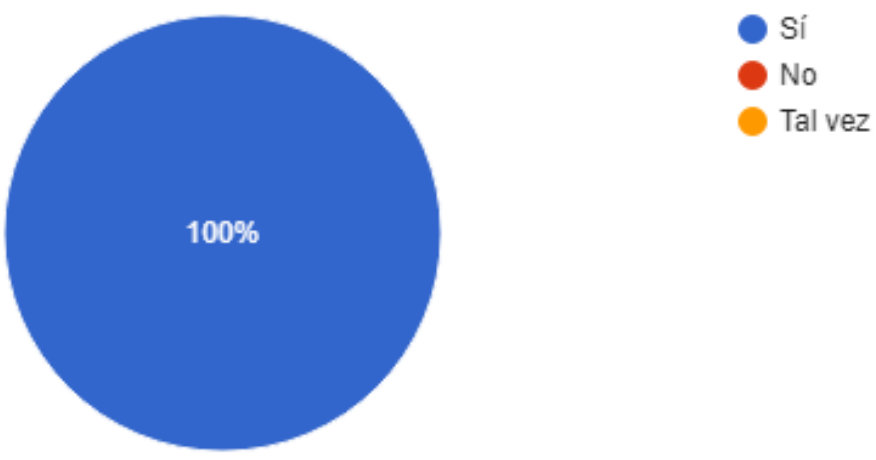

En la conceptualización de este eje, los participantes consideran lo hecho como un paso en la "trayectoria" de un nuevo modo de pensar la medición comunicacional. "No hay forma de volver atrás, recomiendan "seguir trabajando en la difusión y divulgación de la metodología" y "del sistema".

Respecto de la valorización de los aspectos a los que aporta el sistema de medición comunicacional, se visualizan en la Figura 9. 
REVCOM | ISSN 2451-7836 | Año 4, \#8 | mayo de 2019 | Contribuciones | e008

Figura 9. Distribución de la valorización del aporte del sistema de medición comunicacional a distintos parámetros

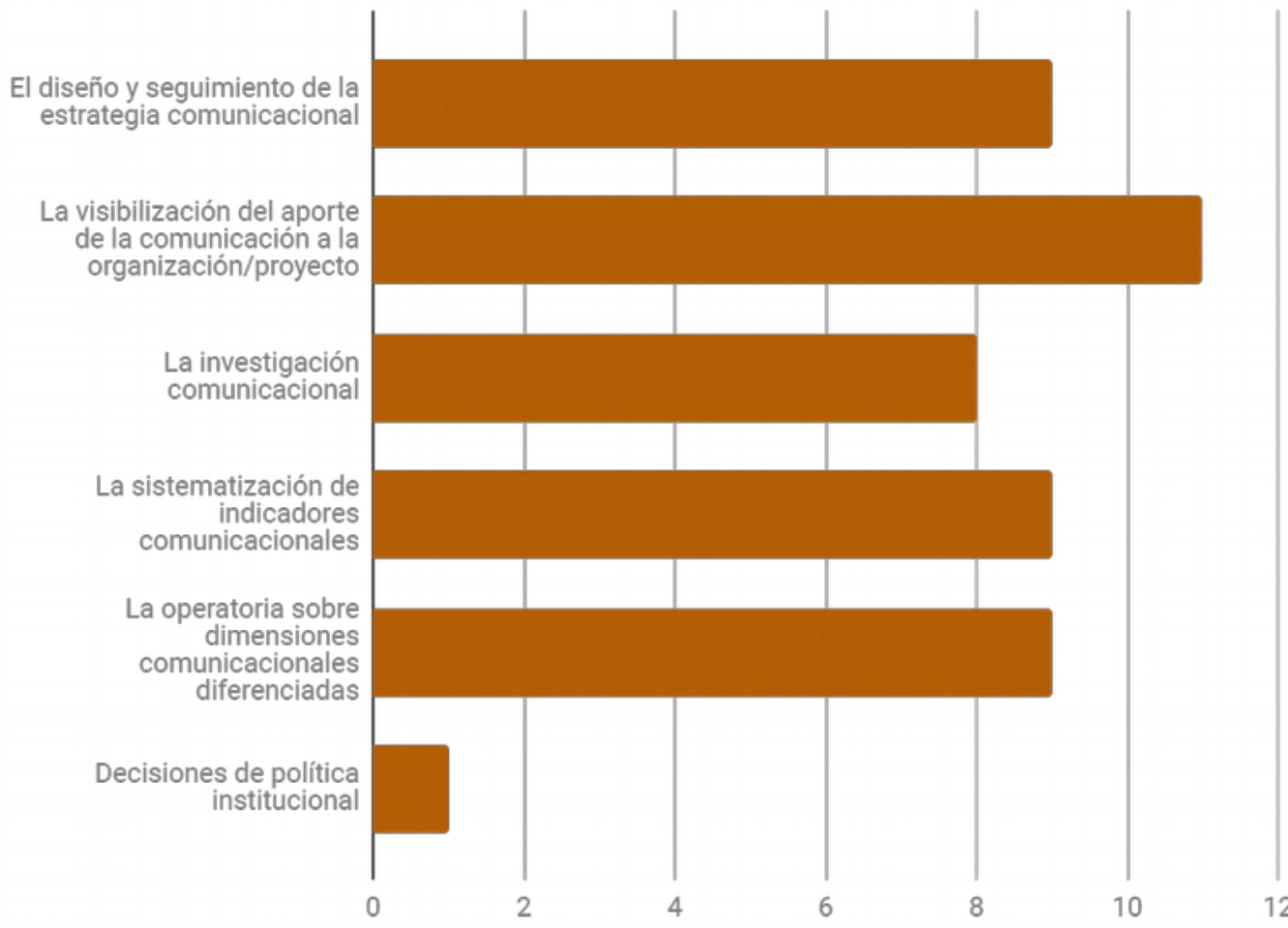

La visibilización del aporte de la comunicación en las organizaciones y proyectos es mencionada como lo más interesante del sistema de medición comunicacional. El diseño y seguimiento de la estrategia comunicacional mientras ocurre, la sistematización de indicadores comunes y la posibilidad de operar sobre diferentes dimensiones de la comunicación a partir del registro complejo de las acciones, son otros de los aspectos valorados. En la opción "Otros" se mencionó que el sistema aporta a "decisiones de política institucional".

Los participantes identificaron claramente las diferencias existentes entre el sistema de registro IEC y los sistemas habituales de medición comunicacional en sus ámbitos de trabajo (Figura 10). 


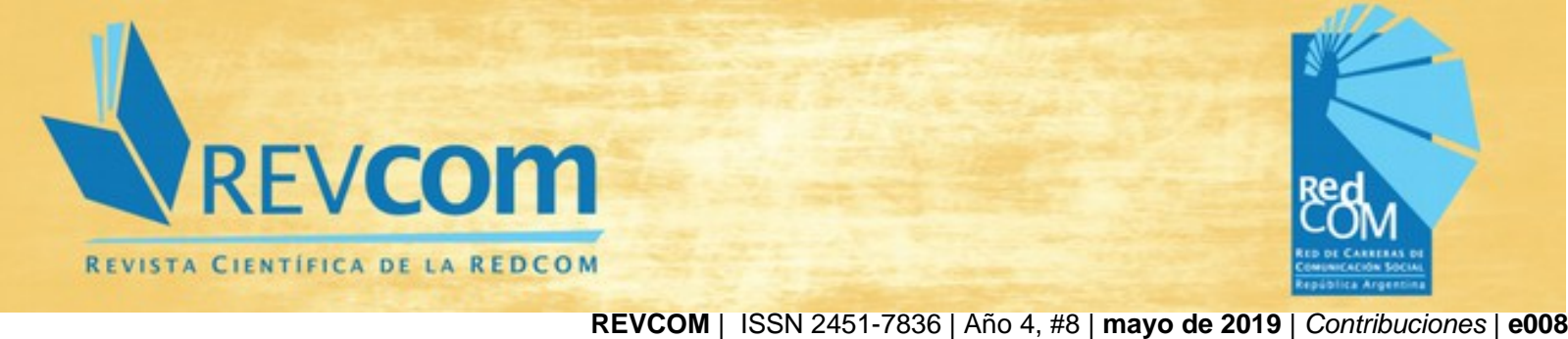

Figura 10. Identificación de diferencias entre el sistema de registro y los sistemas habituales de medición comunicacional en el ámbito propio de trabajo.

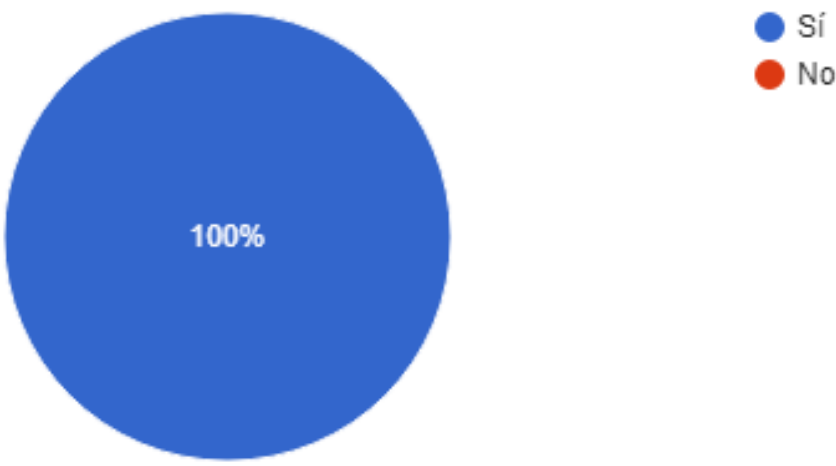

Todos los participantes ven diferencias entre los registros habituales de medición y la modalidad propuesta desde el PID, las que se identifican tanto desde lo conceptual como desde su operatoria. Respecto del primer eje, destacan la multidimensionalidad de la comunicación ("el rescate de dimensiones habitualmente silenciadas"), la mirada holística ("puesta en los procesos y no en las acciones escindidas"), "la centralidad de la transformación buscada", "la superación de lo meramente cuantitativo". En cuanto a la operatoria, valoran especialmente la posibilidad de medición "mientras sucede" -en lugar de a posteriori- y "la devolución automática de los datos". También destacan que facilita la fundamentación de propuestas comunicacionales.

Respecto del eje de discusión acerca de la flexibilidad del sistema de medición, se presentan las consideraciones de los participantes del grupo en la figura 11.

Figura 11. Consideración acerca de la facilitación del monitoreo de una estrategia comunicacional mientras se desarrolla.

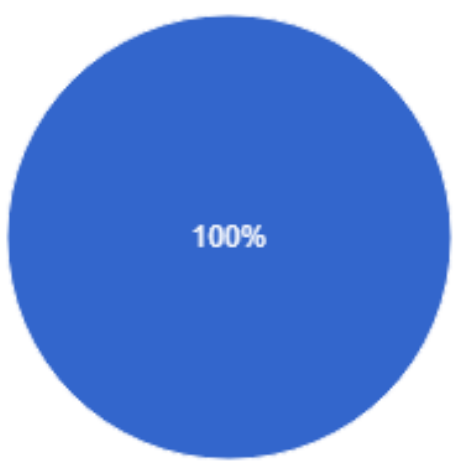


Esta ventaja ya había sido mencionada en la pregunta anterior por varios de los participantes. En su justificación hacen referencia a la posibilidad de: "visibilizar ajustes durante el proceso", "incorporar redireccionamientos y el entusiasmo que provocan estos intercambios en el equipo interdisciplinario a partir de la información emergente del sistema". También se menciona que "los participantes pudieron constatar algunas de las transformaciones buscadas durante el desarrollo de la estrategia comunicacional y registraron cambios en las VTC en el marco del mismo proyecto".

Se mencionan: "La carga pudo reflejar la visión del programa que habíamos reconocido en la VTC." "Doble reflexión: no sólo me pongo de acuerdo en cómo jerarquizar, sino que además sinérgicamente voy operando en el territorio". "Vivencié con entusiasmo la VTC en el proyecto". "La mirada compartida y su capacidad de organización". "Hubo reflexión en el marco del equipo. Un despliegue hermoso de ver".

\section{Conclusiones}

En este trabajo hemos descripto las características del proceso de investigación enactiva en comunicación en 7 proyectos caso a partir de contrastar las percepciones y las experiencias de los investigadores participantes en los distintos equipos y en torno a los interrogantes planteados.

En los primeros apartados de este documento sintetizamos algunos antecedentes propios de la IEC necesarios para comprender las operaciones típicas en una investigación de este tipo en el marco de estudios interdisciplinarios.

Los resultados del análisis de los proyectos se integran en tablas comparativas siguiendo las 7 operaciones del diseño de estrategias de comunicación como algoritmos fluidos correlacionando las técnicas IEC aplicadas (Tabla 6) y las valoraciones globales de los participantes en los proyectos caso examinados (Figura 3).

El estudio muestra como principales resultados: la ponderación de la integración de la comunicación a proyectos de investigación interdisciplinarios (Figura 2 y Tabla 4) en distintos ámbitos y organizaciones (Tabla 2 y Tabla 3) y la valoración de la IEC que los investigadores participantes otorgan a las metodologías, técnicas, instrumentos y herramientas utilizadas (Figura 4).

Se pondera a la IEC como una metodología que contempla e integra la multidimensionalidad del problema, incluye la complejidad de la situación, no es estática y se 
ajusta a cada caso (Tabla 7 y Figura 6). La valoración del software IEC resalta que permite realizar monitoreo y seguimiento online de las transformaciones comunicacionales que se van registrando en el territorio investigado. (Figura 10).

El análisis de la percepción de los investigadores de los equipos interdisciplinarios de los proyectos examinados acerca de la aplicación de técnicas de comunicación estratégica y software IEC arroja además los siguientes resultados iniciales:

- El aporte de las metodologías y las técnicas IEC resulta claramente identificado en los entrevistados participantes de los proyectos (Figuras 1 a 5).

- Desde la percepción de los usuarios de distintas disciplinas, los resultados evidencian valoración positiva (Figura 2).

- E I software IEC utilizado en proyectos que lo aplicaron parcialmente (sólo una dimensión o sólo algunas técnicas IEC) (Tabla 6) fue valorado positivamente por los encuestados en el 92,3\% de los casos (Figura 4).

- Desde la percepción de los usuarios de distintas disciplinas la aplicación de IEC se valora positivamente ( Figura 2 y Figura 4).

- Participaron aplicando las técnicas IEC investigadores de 32 disciplinas distintas (Tabla 4). En los 7 proyectos caso valoraron positivamente el sistema de medición comunicacional (Figura 11).

- La IEC se vincula a "complejidad" y "oportunidad" (Figura 7). Lo más destacado por los usuarios es la versatilidad de la herramienta, permitiendo su uso aún cuando no se implementen todos los pasos de una IEC (Tabla 6).

- Entre las técnicas IEC se valora especialmente la Versión Técnica Comunicacional y el Árbol de Soluciones (Tabla 2 y Figura 11).

- La visibilización del aporte de la comunicación en la organización (Figura 9) es el aspecto más destacado por los usuarios de técnicas IEC.

- La aplicación parcial de técnicas IEC no se correlaciona con percepciones negativas acerca de la metodología (Tabla 6, Figura 7 y Figura 8 ).

La consideración de la dimensión comunicacional en proyectos inter y transdisciplinarios es reciente. Quedará pendiente para siguientes investigaciones: La ampliación de la muestra para incluir proyectos caso de ámbitos y temáticas no considerados en este estudio y observar si la aplicación de las operaciones cognitivas del algoritmo fluido en el diseño de estrategias de comunicación se sostiene en el tiempo en proyectos que ya no cargan en el software IEC, 


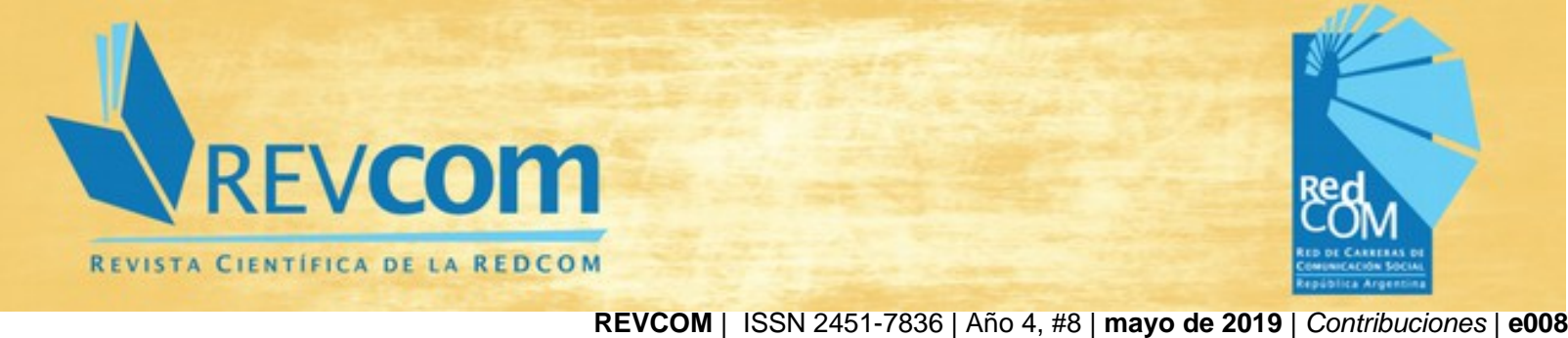

REVCOM | ISSN 2451-7836 | Año 4, \#8 | mayo de 2019 | Contribuciones | e008

analizando su potencial para el autoaprendizaje de la metaperspectiva de la comunicación estratégica enactiva.

\section{BIBLIOGRAFÍA}

Massoni, S. (2018) "Investigación enactiva en comunicación, metodologías participativas y asuntos epistemológicos" en Revista Latinoamericana de Ciencias de la Comunicación Año XV № 28, ALAIC, enero - junio 2018. ISSN 1807- 3026

Massoni, S. (2016). Avatares del comunicador complejo y fluido. Del perfil del comunicador social y otros devenires. Quito, Ecuador. Ediciones Ciespal.

Massoni, S. (2013). Metodologías de la Comunicación estratégica: del inventario al encuentro sociocultural. Rosario, Argentina. Homo Sapiens Ediciones.

Massoni, S. (2003) Estrategias de comunicación: un modelo de abordaje de la dimensión comunicacional para el desarrollo sostenible entendido como cambio social conversacional. Resumen de Tesis doctoral en Revista científica Temas y Debates Universidad Nacional de Rosario, Rosario, Argentina.

Massoni, S. y Margherit, L. (2016) Despliegue, seguimiento y evaluación de la estrategia comunicacional de un proyecto agroforestal mediante metodología de investigación enactiva en comunicación. En libro memorias del XII Congreso Nacional y V Internacional Sobre Democracia: la democracia por venir: elecciones, nuevos sujetos políticos, desigualdades, globalización; compilado por Franco Bartolacci [et al.]. - 1a ed . - Rosario: UNR Editora. Editorial de la Universidad Nacional de Rosario. Libro digital, ISBN 978-987-702-192-9 http://www.fcpolit.unr.edu.ar/memoriascsd2016/

Massoni, S.; Piola, M.; Mascotti, M.; Margherit, L.; Spagnolo, J.; Gerson, E.; Menarvino, B. (2017) Medir la comunicación desde lo vivo. Indicadores comunicacionales en dimensiones múltiples. Editorial UNR: Rosario.

Massoni, S.; Piola, M.; Mascotti, M.; Margherit, L.; Spagnolo, J.; Bussi, M. (2018). PID 231: "Comunicación estratégica: Indicadores comunicacionales en dimensiones múltiples. Fase 2". Sistematización del Workshop de integración. Documento interno.

Artículo recibido el 14-03-2019 | Aceptado el 29-04-2019 | Publicado 26-05-2019

http://perio.un/p.edu.ar/ojs/index.php/revcom/ Esta obra está bajo una Licencia Creative Commons Atribución-NoComercial-SinDerivar 4.0 Internacional 